\title{
Diabetes telemedicine clinic implementation during the COVID-19 virus outbreak in Saudi Arabia
}

\begin{abstract}
Background: Saudi Arabia implemented a nationwide lockdown to slow the spread of the COVID-19 after a global pandemic has been declared by the World Health Organization. Diabetes patients are one of the most vulnerable chronic illness groups to the complications of COVID-19 virus, thus the necessary to implement a tele-medicine clinic during the lockdown.
\end{abstract}

Methods: A cross-sectional observational study, the study was done during the period from October to December 2020. We used convenience sampling to select participants who attended the clinics of the Diabetes Care Center at King Salman Hospital, Riyadh, Saudi Arabia. A total of 375 patients participated in the study.

Results: The study included 375 participants around $60 \%$ were female participants. The age of almost one-third of them $(33.9 \%)$ ranged between 51 and 60 years. Most of the participants were type 2 diabetic patients $(85.3 \%)$, and lived in Riyadh city $(97.6 \%)$. Vast majority of participants $(99.5 \%)$ were follow-up patients and reported telemedicine visit by physicians $(98.9 \%)$. Patients' satisfaction questions showed that majority of the participants either strongly agreed or agreed with the statements that they were satisfied with the quality of the audio during the virtual visit (92\%), use of telemedicine was essential in maintaining health during the COVID-19 outbreak $(90.1 \%)$, the quality of the medical care provided during the virtual visit $(88.3 \%)$, the clarity of the management plan discussed with the heath care practitioner during the virtual visit $(87.7 \%)$, the tele-medicine visit was as good as a regular in person visit $(81.5 \%)$. Also, majority of the participants recommend making diabetes tele-medicine clinic as an available option for patients with diabetes after the COVID-19 outbreak is over $(81.5 \%)$.

Conclusion: The COVID-19 pandemic has urged the transition from in person clinical visits to tele-medicine clinics and showed that it is feasible and effective to have the option of tele-medicine for diabetes clinics in Saudi Arabia. The majority of diabetic patients reported high levels of satisfaction with the tele-medicine clinic.

Keywords: COVID-19, diabetes, telemedicine, telehealth, patient satisfaction, Saudi Arabia
Volume 8 Issue I - 202 |

\author{
Eman Sheshah,' Khalid Kelis,' Najim \\ Abdulwahid,' Nahla Alswaied,' Reem Aman,' \\ Mohammed Alghamdi,' Rabab Hassanien,' \\ Amira Abbas,' Lamiaa Fathy,' Abdulaziz \\ Aldokhail,' Abdulaziz Alzahrany,' Jawaher \\ Alokail,' Dalal Al-Qaisi,' Amira Basha,' \\ Ghassan Aldekhayel,' Amal Azizi' \\ 'Diabetes Care Center, King Salman Hospital, Saudi Arabia \\ 2Pediatric Department, King Salman Hospital, Saudi Arabia
}

Correspondence: Ghassan Aldekhayel, Diabetes Care Center, King Salman Hospital, Riyadh, Saudi Arabia,Tel 00966555442808 , Email dr.gass@hotmail.com

Received: February 26, 202 I | Published: March 29, 202 I
Abbrevations: COVID-19, coronavirus disease 2019; DM, diabetes mellitus; HbA1c, glycated hemoglobin level; HCP, healthcare practitioner; IQR, interquartile range; $\mathrm{SD}$, standard deviation

\section{Background}

In March 2020, a global pandemic has been declared by the World Health Organization after cases of coronavirus disease 2019 (COVID-19) were confirmed throughout the world. Many counties such as Saudi Arabia implemented a nationwide lockdown to slow the spread of the COVID-19 novel virus. ${ }^{1,2}$ Diabetes mellitus (DM) patients were categorized as one of the most vulnerable chronic illness group to the complications of COVID-19 virus. ${ }^{3}$ Therefore, it was necessary for DM patients to avoid clinical visits to minimize the risk of getting infected with COVID-19 and prevent the spread of coronavirus. Meanwhile, leaving diabetes patients with no followup and management lead to uncontrolled diabetes which can cause many chronic macrovascular and microvascular complications. ${ }^{4,5}$ Therefore, in many countries healthcare providers worldwide had to use tele-medicine clinics in order to follow up with their diabetic patients. Studies have shown the effectiveness of tele-medicine in the management diabetes patients and the reduction of glycated hemoglobin level (HbA1c), in both type 1 and type 2 diabetes patients. ${ }^{6,7}$
In Saudi Arabia, during the coronavirus lockdown a study showed a significant reduction in medication compliance and strongly recommended the follow up of diabetes patients using telemedicine. ${ }^{8}$ Thus, the Diabetes Care Center at King Salman Hospital among other healthcare facilities in Saudi Arabia implemented a tele-medicine clinical to follow up their patients during the lockdown and had medication delivered by hospital staff to patients' houses. ${ }^{9}$ In that period, the Diabetes Care Center followed around 13,000 patients though its tele-medicine clinic and continue to have a tele-medicine clinic as well as regular clinic appointments after the lockdown. The Diabetes Care Center at King Salman Hospital healthcare workers used to conduct the visual clinics either Audio calls only through calling the patient on their personal phone or Video and Audio calls using ANAT application depending on the patients' preference. ANAT is a smartphone application which was developed by the Saudi Ministry of Health for e-consultations and issuing prescriptions. ${ }^{10,11}$

\section{Aim and objectives}

The main aim of the study is to test the effectiveness of telemedicine clinic for diabetic patients. In order to reach this aim, the first objective was to evaluate patient satisfaction. The second objective was to assess the factors associated with the satisfaction of the patients with tele-medicine clinic. 


\section{Methodology}

This research study was designed as a cross-sectional observational study. The study was done during the period from October to December 2020. We used convenience sampling to select participants who attended the clinics of the Diabetes Care Center at King Salman Hospital, Riyadh, Saudi Arabia. A total of 375 patients participated in the study, which is a representative sample size according to Openepi sample calculator. ${ }^{12}$ The inclusion criteria for the study were adult endocrine patients who had medical consultations from March to August in the virtual clinic. The exclusion criteria for the study were patients under 18 years old. An informed consent was signed by each participant after agreeing to participate.

\section{Research tool}

A well designed previously developed questionnaire was filled by the investigators, the questionnaire included some demographic questions such as age, gender and city of residence. Other questions included the diagnosis, duration of diabetes, type of visit (new or follow-up patient), and healthcare practitioner (HCP) who conducted the visual clinic. The focus of the questionnaire was on satisfaction questions with the virtual clinic. ${ }^{9}$ Also, the most recent HbAlc test result was documented for each participant.

\section{Statistical analysis}

Data entry and statistical analysis were performed using the Statistical Package for Social Sciences, software, version 26. Categorical variables were described in the form of frequency and percentage while continuous variables were described by mean, standard deviation, median and interquartile range (IQR). Total satisfaction score was tested for normality and found abnormally distributed as evidenced by significant Kolmogrov-smirnov test. None-parametric statistical tests were applied for comparisons as Mann-Whitney test was used to compare two groups while KruskalWallis test was used to compare more than two groups and Spearman's test was applied to test for correlation between $\mathrm{HbA} 1 \mathrm{c}$ and total telemedicine satisfaction score, $\mathrm{p}$-vales $<0.05$ was used to determine statistical significance.

\section{Results}

The study included 375 participants. Their personal and background characteristics are summarized in Table 1 . The age of almost one-third of them (33.9\%) ranged between 51 and 60 years and that of $23.7 \%$ ranged between 41 and 50 years. Females represent $62.7 \%$ of them. Majority of the participants $(97.6 \%)$ live in Riyadh and diagnosed with type 2 diabetes mellitus (85.3\%). More than half of the participants $(52.5 \%)$ diagnosed for $6-15$ years. Vast majority of them $(99.5 \%)$ were in follow-up visits and reported telemedicine visit by physicians (98.9\%). The HbAlc among the participants ranged between 4.6 and 17.8 with a mean \pm standard deviation (SD) of $8.5 \pm 1.9$. It is abnormally distributed as indicated by significant Kolmogrov-Smirnov test Figure 1.

\section{Experience with tele-health clinic}

As illustrated in Figure 2, vast majority of the participants (97.1\%) reported that the method used for communication in the tele-health clinic was audio call. More than half of the participants $(56.8 \%)$ reported history of getting medication home delivery as seen in Figure 3. History of previous ever using a virtual clinic (a tele-medicine clinic) was observed among $15.7 \%$ of the participants as displayed in Figure 4.
Table I Personal and background characteristics of the participants $(n=375)$

\begin{tabular}{|c|c|c|}
\hline & Frequency & Percentage \\
\hline \multicolumn{3}{|l|}{ Age in years } \\
\hline $20-30$ & 23 & 6.1 \\
\hline $31-40$ & 24 & 6.4 \\
\hline $41-50$ & 89 & 23.7 \\
\hline $51-60$ & 127 & 33.9 \\
\hline $61-70$ & 84 & 22.4 \\
\hline$>70$ & 28 & 7.5 \\
\hline \multicolumn{3}{|l|}{ Gender } \\
\hline Male & 140 & 37.3 \\
\hline Female & 235 & 62.7 \\
\hline \multicolumn{3}{|l|}{ City of residence } \\
\hline Riyadh city & 366 & 97.6 \\
\hline Outside Riyadh city & 9 & 2.4 \\
\hline \multicolumn{3}{|l|}{ Diagnosis } \\
\hline Type I diabetes & 28 & 7.5 \\
\hline Type 2 diabetes & 320 & 85.3 \\
\hline Gestational diabetes & 3 & 0.8 \\
\hline Endocrine disease & 24 & 6.4 \\
\hline \multicolumn{3}{|c|}{ Duration since diagnosis (years) } \\
\hline$<1$ & 6 & 1.6 \\
\hline 5-Jan & 64 & 17.1 \\
\hline I0-Jun & 94 & 25.1 \\
\hline I5-Nov & 103 & 27.4 \\
\hline $16-20$ & 57 & 15.2 \\
\hline$>20$ & 51 & 13.6 \\
\hline \multicolumn{3}{|l|}{ Type of visit } \\
\hline New patient & 2 & 0.5 \\
\hline Follow-up visit & 373 & 99.5 \\
\hline \multicolumn{3}{|c|}{ Healthcare practitioner who conducting telemedicine visit } \\
\hline Physician & 371 & 98.9 \\
\hline Educator & 4 & I.I \\
\hline
\end{tabular}

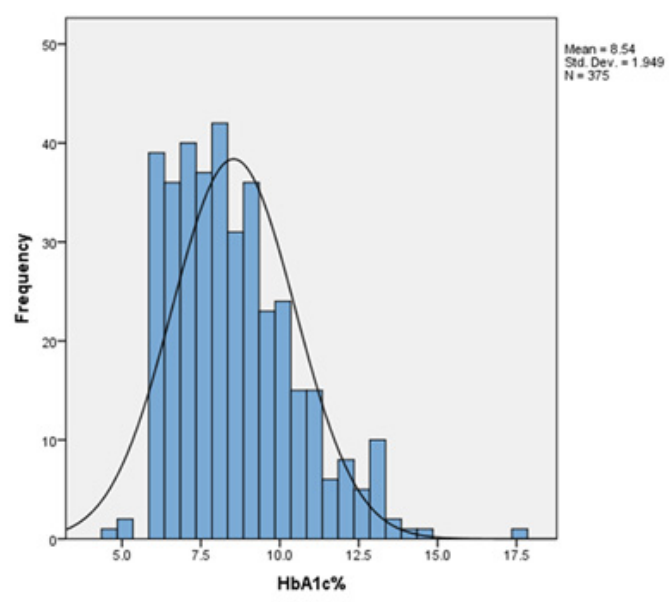

Figure I Level of glycated hemoglobin percentage among the participants. 


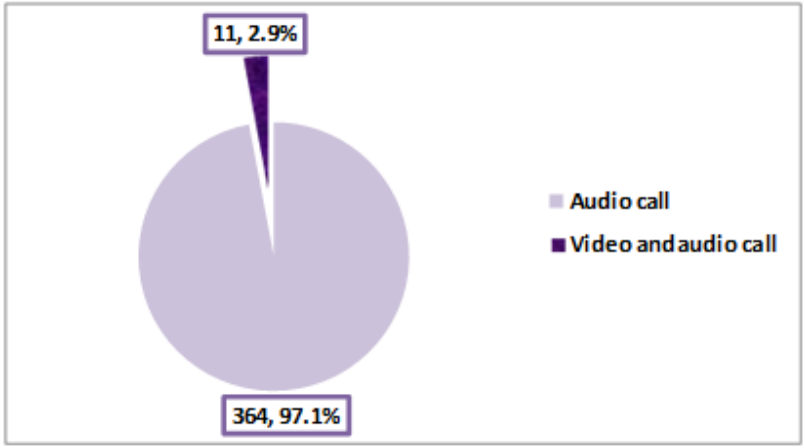

Figure 2 Participants' method of communication used in the tele-health clinic.

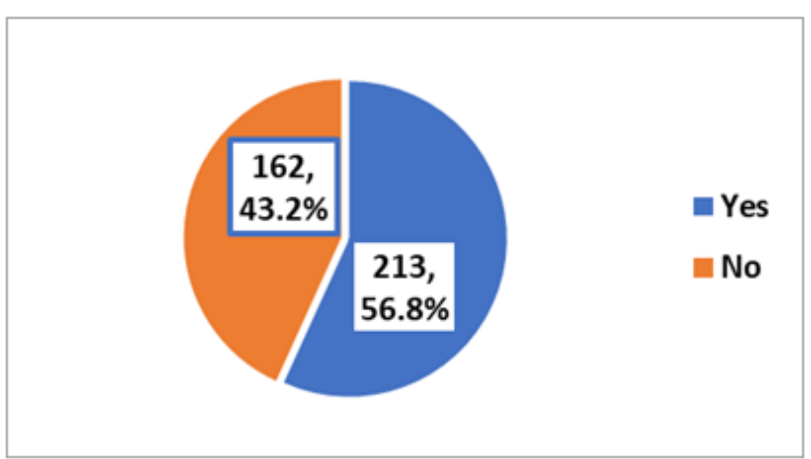

Figure 3 History of getting medication home delivery among the participants.

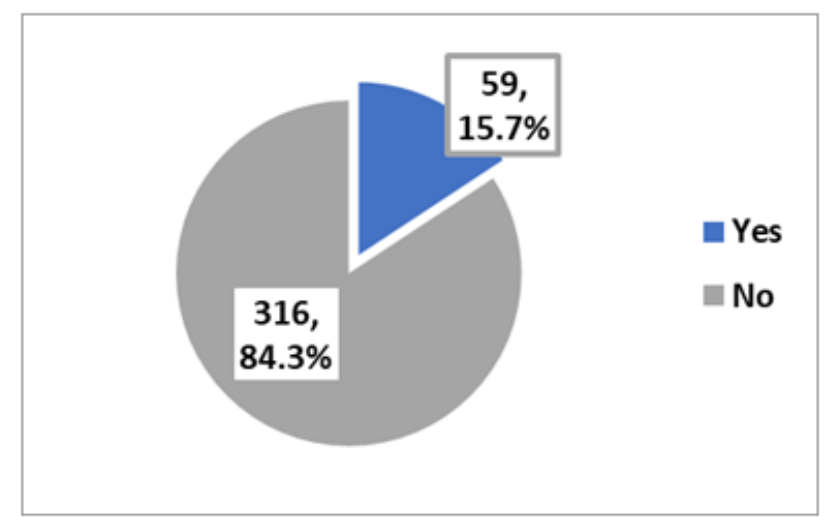

Figure 4 History of previous ever using a virtual clinic (a tele-medicine clinic) among the participants.

\section{Satisfaction with tele-medicine}

From Table 2, majority of the participants either strongly agreed or agreed with the statements that they were satisfied with the quality of the audio during the virtual visit (92\%), use of telemedicine was essential in maintaining health during the COVID-19 outbreak $(90.1 \%)$, the quality of the medical care provided during the virtual visit $(88.3 \%)$, the clarity of the management plan discussed with the HCP during the virtual visit $(87.7 \%)$, the tele-medicine visit was as good as a regular in person visit $(81.5 \%)$. Also, majority of the participants recommend making Diabetes Telemedicine Clinic as an available option for patients with diabetes after the COVID-19 outbreak is over $(81.5 \%)$. Overall, the total satisfaction score ranged between 6 and 30 with a mean \pm SD of $27.4 \pm 4.4$, median and (IQR) of 30 (24-30). It was abnormally distributed as shown by a significant Kolmogrov-Smirnov, $\mathrm{p}<0.001$ Figure 5 .

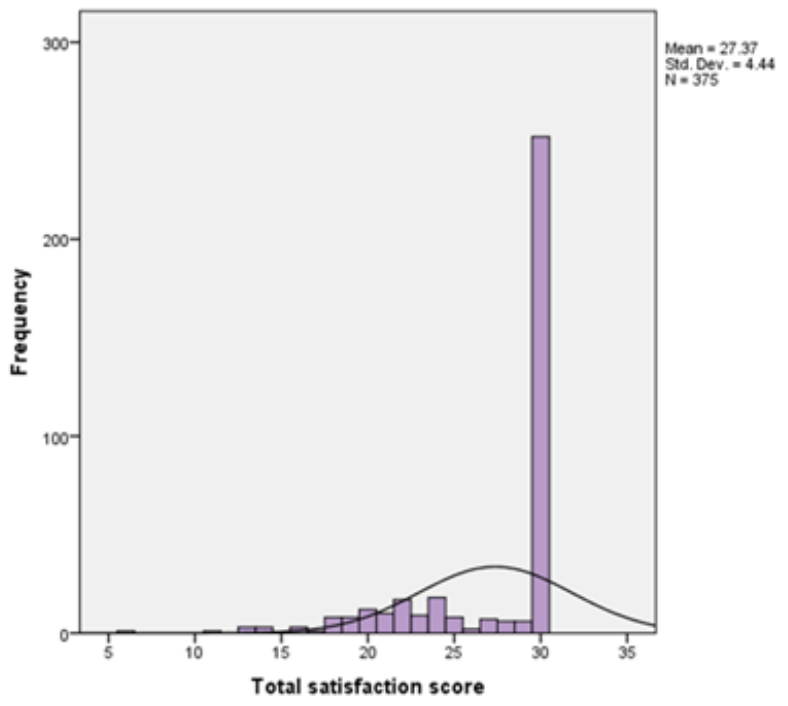

Figure $\mathbf{5}$ Tele-medicine satisfaction score among the participants.

\section{Factors associated with satisfaction with tele-medicine}

Participants diagnosed with gestational diabetes showed the highest satisfaction score (mean rank was 249.50) while those diagnosed with endocrine diseases showed the lowest satisfaction (mean rank was 78.35), $\mathrm{p}<0.001$. Recently diagnosed patients $(<1$ years $)$ had the highest satisfaction score (mean rank was 222.17) while those diagnosed singe 11-15 years expressed the lowest satisfaction score (mean rank=162.01), $\mathrm{p}=0.020$. Follow-up visits' patients were more satisfied with tele-medicine compared to newly diagnosed patients (mean ranks were 188.87 and 25.50 , respectively), $\mathrm{p}=0.011$. Other studied factors were not significantly associated with satisfaction score Table 3. There was negative insignificant correlation between $\mathrm{HbA1c}$ levels and tele-medicine satisfaction score, spearman's correlation coefficient $(r)=-0.080, p=0.122$ Figure 6 .

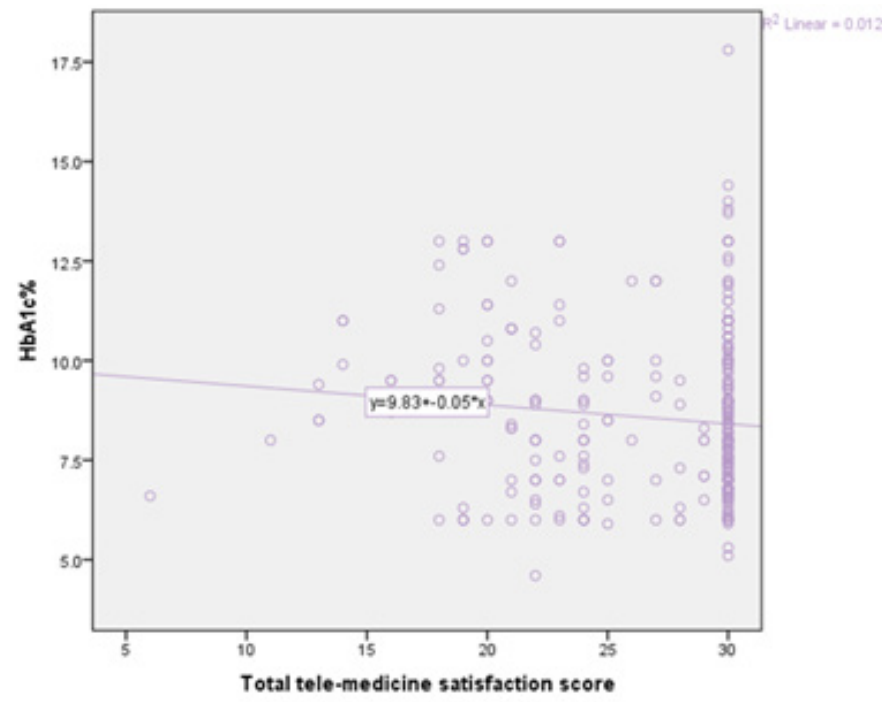

Figure 6 Correlation between glycated hemoglobin level and satisfaction with telemedicine among the participants. 
Table 2 Response of the participants to tele-medicine satisfaction statements

\begin{tabular}{|c|c|c|c|c|c|}
\hline & Strongly agree & Agree & Neutral & Disagree & Strongly disagree \\
\hline & \multicolumn{4}{|l|}{$\mathbf{N}(\%)$} & $\mathbf{N}(\%)$ \\
\hline & & $\mathbf{N}(\%)$ & $\mathbf{N}(\%)$ & $\mathbf{N}(\%)$ & \\
\hline \multirow[t]{2}{*}{ The tele-medicine visit was as good as a regular in person visit } & 268 & 38 & 46 & 19 & 4 \\
\hline & -71.4 & -10.1 & -12.3 & -5.1 & -1.1 \\
\hline \multirow[t]{2}{*}{$\begin{array}{l}\text { Use of telemedicine was essential in maintaining health during the } \\
\text { COVID-19 outbreak }\end{array}$} & 282 & 56 & 29 & 4 & 4 \\
\hline & -75.2 & -14.9 & -7.7 & -1.1 & -1.1 \\
\hline \multirow{2}{*}{$\begin{array}{l}\text { I recommend making Diabetes Telemedicine Clinic an available } \\
\text { option for patients with diabetes after the COVID- I } 9 \text { outbreak is } \\
\text { over }\end{array}$} & 268 & 48 & 34 & 15 & 10 \\
\hline & -71.4 & -12.8 & -9.1 & -4 & -2.7 \\
\hline \multirow[t]{2}{*}{ I am satisfied with the quality of the audio during the virtual visit } & 282 & 63 & 23 & 3 & 4 \\
\hline & -75.2 & -16.8 & -6.1 & -0.8 & $-1 . I$ \\
\hline \multirow[t]{2}{*}{$\begin{array}{l}\text { I am satisfied with the quality of the medical care provided during } \\
\text { the virtual visit }\end{array}$} & 277 & 54 & 38 & 4 & 2 \\
\hline & -73.9 & -14.4 & -10.1 & -1.1 & -0.5 \\
\hline \multirow[t]{2}{*}{$\begin{array}{l}\text { I am satisfied with the clarity of the management plan discussed } \\
\text { with the HCP during the virtual visit }\end{array}$} & 278 & 51 & 35 & 10 & I \\
\hline & -74.1 & -13.6 & -9.3 & -2.7 & -0.3 \\
\hline
\end{tabular}

Table 3 Factors associated with satisfaction with tele-medicine among the participants

\begin{tabular}{|c|c|c|c|c|}
\hline & \multicolumn{4}{|c|}{ Total satisfaction score } \\
\hline & Median & IQR & Mean rank & p-value \\
\hline \multicolumn{5}{|l|}{ Age in years } \\
\hline $20-30(n=23)$ & 30 & $24-30$ & 183.74 & \\
\hline $31-40(n=24)$ & 30 & $22.5-30$ & 183.83 & \\
\hline $4 \mid-50(n=89)$ & 30 & $22-30$ & 172.57 & \\
\hline $51-60(n=127)$ & 30 & $25-30$ & 189 & \\
\hline $61-70(n=84)$ & 30 & $27-30$ & 193.36 & \\
\hline$>70(n=28)$ & 30 & $30-30$ & 223.5 & 0.198 \\
\hline \multicolumn{5}{|l|}{ Gender } \\
\hline Male $(n=140)$ & 30 & $28-30$ & 198.75 & \\
\hline Female $(n=235)$ & 30 & $24-30$ & 181.59 & 0.076 \\
\hline \multicolumn{5}{|l|}{ City of residence } \\
\hline Riyadh city $(n=366)$ & 30 & $24.75-30$ & 188.5 & \\
\hline Outside Riyadh city $(n=9)$ & 30 & $22-30$ & 167.83 & 0.498 \\
\hline \multicolumn{5}{|l|}{ Diagnosis } \\
\hline Type I diabetes $(n=28)$ & 30 & $22-30$ & 178.82 & \\
\hline Type II diabetes $(n=320)$ & 30 & $27-30$ & 196.45 & \\
\hline Gestational diabetes $(n=3)$ & 30 & $30-30$ & 249.5 & \\
\hline Endocrine disease $(n=24)$ & 23 & $19.25-24.75$ & 78.35 & $<0.001$ \\
\hline \multicolumn{5}{|c|}{ Duration since diagnosis (years) } \\
\hline$<1(n=6)$ & 30 & $28.5-30$ & 222.17 & \\
\hline$I-5(n=64)$ & 30 & $28.25-30$ & 201.6 & \\
\hline $6-10(n=94)$ & 30 & $28-30$ & 202.01 & \\
\hline
\end{tabular}


Table continued...

\begin{tabular}{|c|c|c|c|c|}
\hline & \multicolumn{3}{|c|}{ Total satisfaction score } & \multirow[b]{2}{*}{ p-value } \\
\hline & Median & IQR & Mean rank & \\
\hline \multicolumn{5}{|l|}{ Age in years } \\
\hline $11-15(n=103)$ & 30 & $21-30$ & 162.01 & \\
\hline $16-20(n=57)$ & 30 & $25-30$ & 186.87 & \\
\hline$>20(n=51)$ & 30 & $27-30$ & 194.85 & 0.02 \\
\hline \multicolumn{5}{|l|}{ Type of visit } \\
\hline New patient $(n=2)$ & 19 & $18-19$ & 25.5 & \\
\hline Follow-up visit $(n=373)$ & 30 & $25-30$ & 188.87 & 0.011 \\
\hline \multicolumn{5}{|c|}{ Healthcare practitioner who conducting telemedicine visit } \\
\hline \multicolumn{5}{|l|}{ Physician $(n=371)$} \\
\hline \multirow[t]{2}{*}{ Educator $(n=4)$} & 30 & $24-30$ & 188.15 & \\
\hline & 27.5 & $25-30$ & 174 & 0.756 \\
\hline \multicolumn{5}{|c|}{ Method of communication used in the tele-health clinic } \\
\hline \multicolumn{5}{|l|}{ Audio call $(n=364)$} \\
\hline \multirow[t]{2}{*}{ Video and audio call $(n=I I)$} & 30 & $24-30$ & 188.28 & \\
\hline & 30 & $27-30$ & 178.59 & 0.726 \\
\hline \multicolumn{5}{|c|}{ History of getting medication home delivery } \\
\hline \multicolumn{5}{|l|}{ No $(n=162)$} \\
\hline \multirow[t]{2}{*}{ Yes $(n=2 \mid 3)$} & 30 & $24-30$ & 178.74 & \\
\hline & 30 & $25-30$ & 195.04 & 0.084 \\
\hline \multicolumn{5}{|c|}{ History of previous ever using a tele-medicine clinic } \\
\hline \multicolumn{5}{|l|}{ No $(n=3 \mid 6)$} \\
\hline \multirow[t]{2}{*}{ Yes $(n=59)$} & 30 & $24-30$ & 184.8 & \\
\hline & 30 & $29-30$ & 205.12 & 0.113 \\
\hline
\end{tabular}

\section{Discussion}

The importance of implementing a tele-medicine clinic to follow up diabetic patients in order to reduce the risk of coronavirus infection among the vulnerable diabetic patients was shared by other published research. ${ }^{8,13}$ In the present research, the majority of participants either strongly agreed or agreed with the satisfaction questions about the diabetes tele-medicine this finding positively correlate with a similar study done in Saudi Arabia. ${ }^{9}$ Tele-medicine clinics is well tested and proven to be effective diabetes before the COVID-19 pandemic. ${ }^{6,7}$ Meanwhile, the transition from clinic visits to tele-medicine clinics due to coronavirus pandemic gave experience and infrastructure to healthcare facilities to use tele-medicine clinics after the pandemic. ${ }^{9,14}$ The Diabetes Care Center at King Salman Hospital continue to have a tele-medicine clinic after the lockdown and plans to continue to follow up with patients through tele-medicine clinics.

\section{Conclusion}

The COVID-19 pandemic has urged the transition from in person clinical visits to tele-medicine clinics which gave healthcare providers in Saudi Arabia the experience and the infrastructure to follow up patients through tele-medicine clinics after the pandemic. The implementation of tele-medicine clinics during the COVID-19 pandemic showed that is feasible and effective to have the option of tele-medicine for diabetes clinics in Saudi Arabia. The majority of diabetic patients showed acceptance for tele-medicine clinics and reported high levels of satisfaction with the tele-medicine clinic.

\section{Study limitations}

The study lacked the necessary funding to support the research to have a prospective study for the variables included in this study.

\section{Funding}

None.

\section{Acknowledgements}

None.

\section{Conflicts of interest}

The authors declare that they have no conflicts of interest.

\section{References}

1. World health organization. World health organization director-general's opening remarks at the media briefing on COVID-19. 2020.

2. Barry M, Ghonem L, Alsharidi A, et al. Coronavirus disease 2019 (COVID-19) pandemic in the kingdom of Saudi Arabia: mitigation measures and hospitals preparedness. J Nature Sci Med. 2020;3(3):155158 
3. Muniyappa R, Gubbi S. COVID-19 pandemic, coronaviruses, and diabetes mellitus. Am J Physiol Endocrinol Metab. 2020;318(5):E736E741.

4. Girach A, Manner D, Porta M. Diabetic microvascular complications: can patients at risk be identified? a review. Int $J$ Clin Pract. 2006;60(11):1471-1483.

5. ADA. 11. Microvascular complications and foot care: standards of medical care in diabetes-2019. Diabetes Care. 2019;42(Suppl 1):S124S138

6. Lee SWH, Ooi L, Lai YK. Telemedicine for the management of glycemic control and clinical outcomes of type 1 diabetes mellitus: a systematic review and meta-analysis of randomized controlled studies. Front Pharmacol. 2017;8:330.

7. Liang X, Wang Q, Yang X, et al. Effect of mobile phone intervention for diabetes on glycaemic control: a meta-analysis. Diabet Med. 2011;28(4):455-463.

8. Alshareef R, Al Zahrani A, Alzahrani A, et al. Impact of the COVID-19 lockdown on diabetes patients in Jeddah, Saudi Arabia. Diabetes Metab Syndr. 2020;14(5):1583-1587.
9. Al-Sofiani ME, Alyusuf EY, Alharthi S, et al. Rapid implementation of a diabetes telemedicine clinic during the coronavirus disease 2019 outbreak: our protocol, experience, and satisfaction reports in Saudi Arabia. J Diabetes Sci Technol. 2020;15(2):329-338.

10. Al-Rabiah: Doctors can issue prescriptions via anaat app. Saudi ministry of health. 2020 .

11. Hassounah M, Raheel H, Alhefzi M. Digital response during the COVID-19 pandemic in Saudi Arabia. $J$ Med Internet Res. 2020;22(9):e19338.

12. OpenEpi. Open source statistics for public health: OpenEpi, Version 3. 2019.

13. Galiero R, Pafundi PC, Nevola R, et al. The importance of telemedicine during COVID-19 pandemic: a focus on diabetic retinopathy. J Diabetes Res. 2020;2020:9036847.

14. Alghamdi S, Alqahtani J, Aldhahir A. Current status of telehealth in Saudi Arabia during COVID-19. J Family Community Med. 2020;27(3):208-211. 